\title{
Proteomics and Human Diseases
}

\author{
Rosa Lippolis $^{1 *}$ and Maria De Angelis ${ }^{2}$
}

${ }^{1}$ Institute of Biomembranes and Bioenergetics, Italian National Research Council, (CNR) Bari, Italy

${ }^{2}$ Department of Soil, Plant and Food Sciences, University "A Moro", Bari, Italy

\begin{abstract}
Proteomics, the large scale study of proteins and protein variations, contributes to a better understanding of the molecular basis of variability in susceptibility to diseases that are associated with genetic diversity and environmental factors. The development of proteomic technologies has permitted the unprecedented large-scale identification of proteins in any biological system. Human proteomics point out physiological conditions that could greatly impact on medicine. This knowledge has the potential to decode the pathogenic mechanisms underlying diseases, elucidate potential risk factors and molecular targets for drug development and therapeutic interventions and identify promising biomolecules that could be developed for diagnostic and prognostic purposes and for improved disease management strategies. Thus proteomics can translate basic scientific discoveries into the clinical practice for precision medicine. This report provides an overview of targeted proteomics in biomedical clinical science by focusing on current stateof-the-art relatively to advances in biomedical proteomic applications. Future prospective metaproteomics and proteogenomics studies are highlighted.
\end{abstract}

Keywords: Cancer proteomics; Heart proteomics; Proteomic of neurodegenerative diseases; Metaproteomics; Protogenomics

Abbreviations: PTMs: Post-Translational Modifications; DRE: Digital Rectal Examination; TRUS: Trans Rectal Ultrasound; HCC: Hepatocellular Carcinoma; 2DE: Two Dimensional Electrophoresis; MALDI-TOF: Matrix Assisted Laser Desorption Ionization-Time of Flight Mass Spectrometry; DCMP: Dilated Cardiomyopathy; PCTs: Primary Cardiac Tumors; AD: Alzheimer Disease; FTD: Frontotemporal Dementia; ALS: Amyotrophic Lateral Sclerosis; VD: Vascular Dementia; PD: Parkinson's Disease; CJD: CreutzfeldtJakob Disease; SNpc: Central and Peripheral Nervous System; CSF: Cerebrospinal Fluid; GI: The Human Gastro-intestinal; IBDs: Inflammatory Bowel Diseases; CD: Crohn's Disease; UC: Ulcerative Colitis; TCGA: Cancer Genomic Atlas; CPTAC 2: Clinical Proteomics Tumor Analysis Consortium

\section{Introduction}

During the last two decades, genome analyses have resulted in greater knowledge [1,2]. Particular interest is assigned to the genetics of human disease and specific aberrations in the cancer cells genome and other diseases have been identified. Despite tremendous advances in the understanding of the molecular basis of diseases, substantial gaps remain in the knowledge of the molecular processes involved in pathogenesis and in the development of diagnostic tools for early disease diagnosis and effective strategies for therapeutic interventions. In other words, understanding of the genome alone, i.e., without the necessary knowledge of the encoded gene products, does not permit clear extrapolations regarding the complex biological processes that occur in the cells. It is clear that there is a large gap in predicting phenotype from genotype. Proteins functionally govern cellular processes and execute activities dictated by genes to determine the cellular phenotype and the targets of natural selection. They are involved in virtually every cellular function and processes and perform all the work of biological systems. Post-translational modifications (PTMs) of proteins, such as phosphorylation or glycosylation, are very important for determining protein function. Similarly, the effects of environmental factors or multigenic processes, such as aging or disease, cannot be assessed simply by examining the genome alone. Moreover, variations in the levels of DNA or transcripts do not correlate well with the protein abundance [3]. Genomic sequencing has been a major focus in recent decades [4]; however, genomics alone cannot provide information regarding the dynamics of proteinprotein interactions, which are the key to delineating the biological mechanisms and functional consequences of the expression of the diverse proteins associated with diseases. Proteomics and the socalled 'omics' sciences (metabolome, expressome and interactome, etc.) are aimed at decoding the information contained in the genomic sequences in terms of protein structures and functions. The goal of proteomics is to bridge the gap between genomic information and functional proteins to lay the foundations for an integrated knowledge to understand the biology system dynamics (Figure 1). The emerging proteomic technologies [5] (Figure 2) that are capable of comprehensive measurements of gene products at a systems level $[6,7]$ offer considerable opportunities for an improved understanding of cell biology. Proteomic analyses provide insight that enables the molecular characterization of various human diseases and the ability to decipher the molecular mechanisms dictating the initiation and progression of the disease. Disease involves alterations in protein expression levels. Hence, by studying the change in the abundance of proteins between different cellular states (normal vs. diseased states), proteomics provide insights into the pathophysiological basis of protein target identification and validation for intervention and treatment of disease. Specific biomarkers identified from proteomics may be used as protein signatures to screen new chemical entities for target organ toxicity in preclinical trials and in the development of clinical trials, ensuring their usefulness in the diagnosis and prognosis of diseases. By holistically examining the entire protein profile of cellular tissues treated with

*Corresponding author: Rosa Lippolis, Institute of Biomembranes and Bioenergetics (IBBE), National Research Council (CNR), 70124 Bari - Italy, Tel: +39080 5448509-31; Fax: +39 080 5448538; E-mail: r.lippolis@ibbe.cnr.it

Received January 14, 2016; Accepted March 03, 2016; Published March 10 2016

Citation: Lippolis R, De Angelis M (2016) Proteomics and Human Diseases. J Proteomics Bioinform 9: 063-074. doi:10.4172/jpb.1000391

Copyright: ( 92016 Lippolis R, et al. This is an open-access article distributed under the terms of the Creative Commons Attribution License, which permits unrestricted use, distribution, and reproduction in any medium, provided the original author and source are credited. 


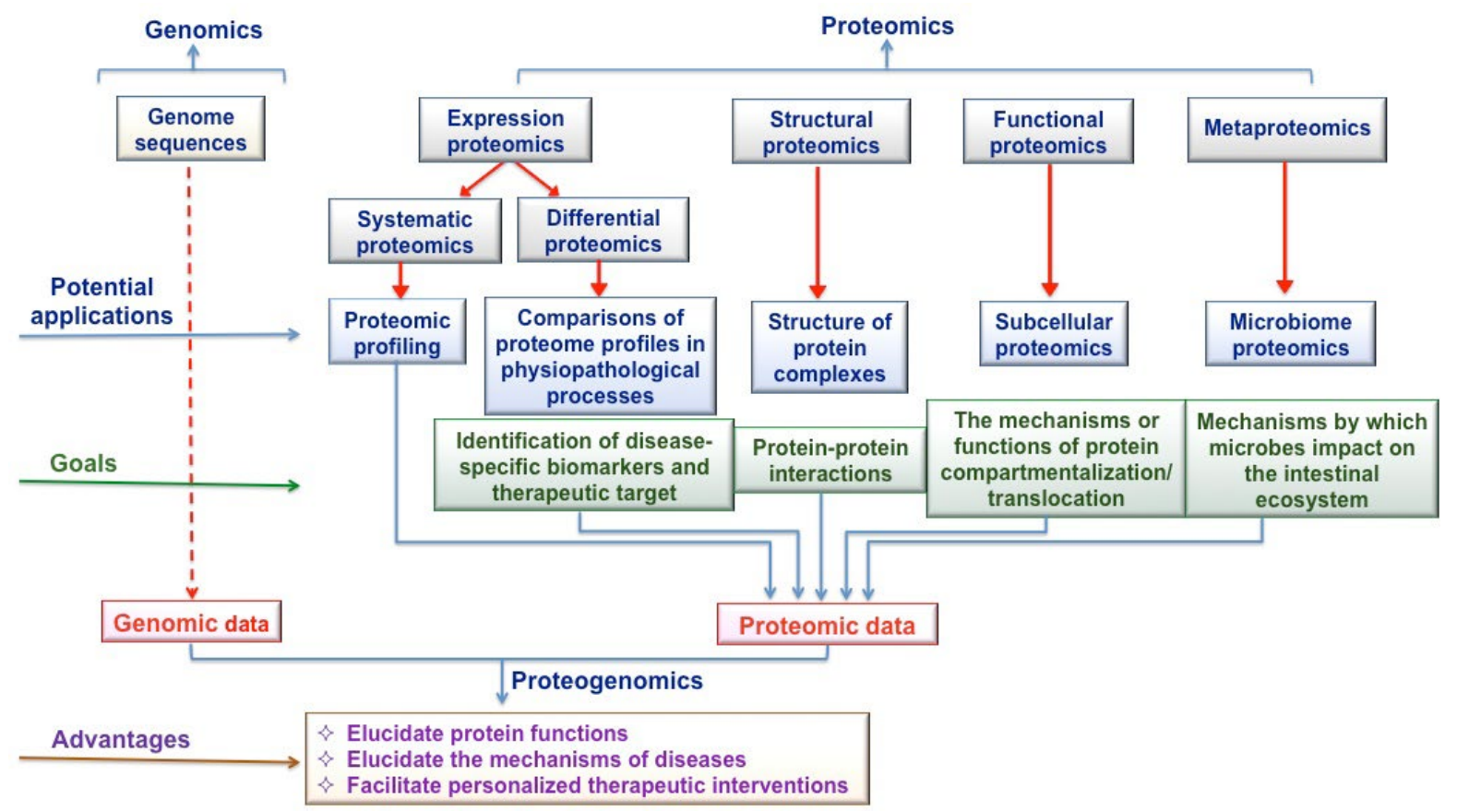

Figure 1: Potential applications of proteomics in clinical research and advantages of integrating proteomic and genomic data.

Technically, proteomics application can be of different types:

1. Expression proteomics (systematic and/or differential), is the study of cell proteome and identification of dysregulated proteins as a function of particular condition (i.e., disease drug, etc.)

2. Structural proteomics is the study of the protein structure and proteins complexes and their subcellular localization.

3. Functional proteomics is an important approach in understanding the functional organization of cells at the molecular level.

The integration of genomic and proteomic data could help to elucidate the functions of proteins in the pathogenesis of diseases, and could lead to the discovery of nove biomarkers of diseases and drug target proteins [27].

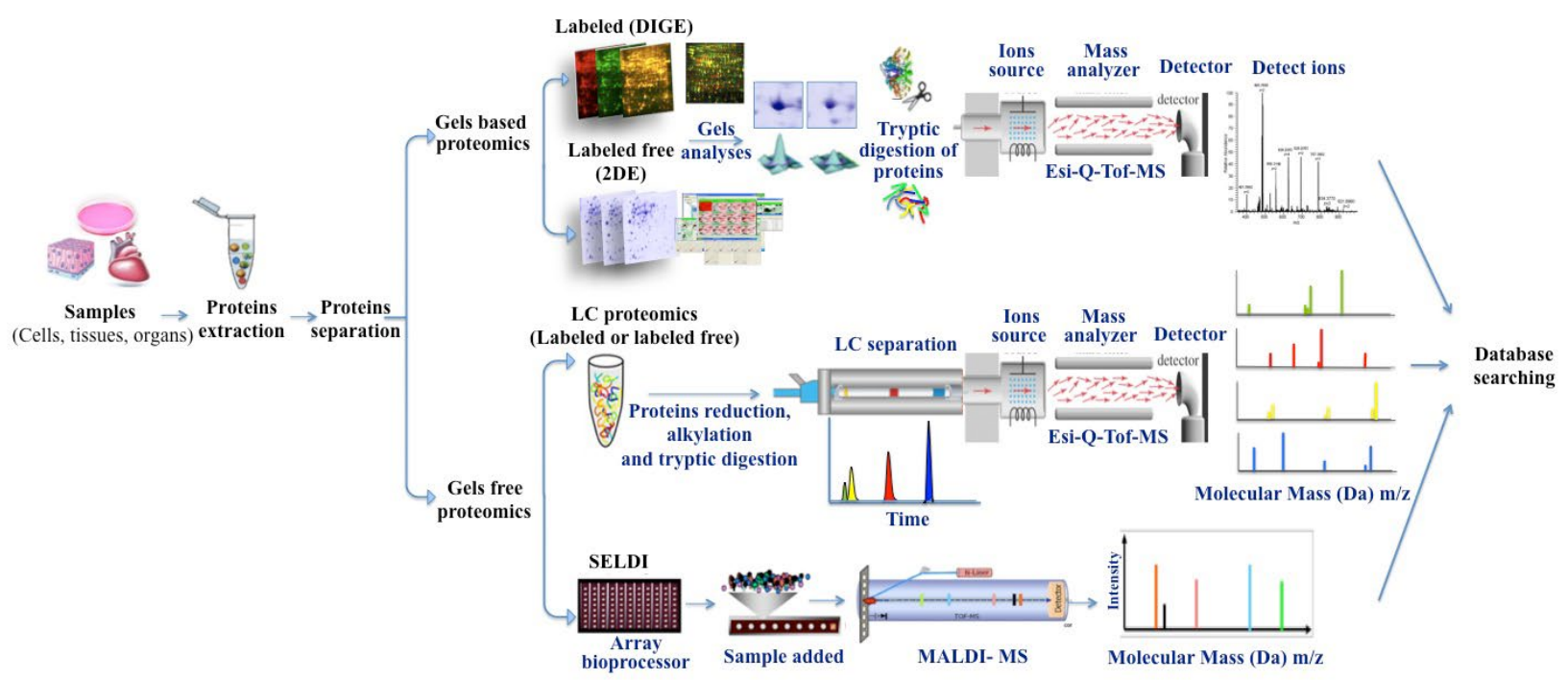

Figure 2: Schematic representation of advanced proteomics technologies.

Both gel-based (one-dimensional [1D] gel electrophoresis, two-dimensional [2D] polyacrylamide gel electrophoresis, 2D difference in-gel electrophoresis [DIGE]) and gel-free (liquid chromatography [LC], capillary electrophoresis) approaches have been developed and utilized in a variety of combinations to separate proteins prior to mass spectrometric analysis. The typical proteomics experiment require of four steps.

Step 1: proteins isolated from cell lysate, body fluid or tissues were separated by both gel based and gel free methods.

Step 2: proteins were enzymatically digested to peptides

Step 3: peptides were analized by either ESI or MADI-MS mass spectrometer.

Step 4: mass spectra of the peptides were matched against protein sequence databases for protein identification. 
drugs or drug candidates, proteomics establishes a comprehensive protein interaction map ('interactomes') related to disease pathways, hence optimizing the drug development process [8]. Results of these proteomic investigations to disease will overcome some of the limitations the current diagnostic and therapeutic methods. The applications of clinical proteomics are direct especially to human cancers, cardiac and neurological diseases that are the most widely occurring pathologies in throughout the world. Brief overviews of the results obtained by proteomic applications in these biomedical areas are provided below. Metaproteomics and proteogenomics studies are also highlighted as new emergenting field of clinical research. The metaproteomics provides new insights into the importance of the gut microbiome in human health. This has established the importance of the gut microbiome in the disease pathogenesis for numerous systemic disease states, such as obesity [9] and cardiovascular disease [10], and intestinal conditions, such as inflammatory bowel disease [11] witch can be associated with an increased risk of colorectal carcinoma [12]. Protogenomic integrate and complete proteomic study by correlating genomic and proteomic data and his directed to a better understanding of the processes that underlie the onset of the disease. In this way, proteomic study of cardiovascular, neurodegenerative and cancer diseases, metagenomics and protogenomic are not so far away.

\section{Cancer Proteomics}

Cancer is a class of complex diseases in which the cells in a specific tissue (or) organ are no longer fully responsive to the signals that regulate cellular differentiation, survival, proliferation and death. The diagnosis and classification of cancer are based on the cellular morphology and histological architecture. However, the applied methods are subjective and prone to variable interpretations, and patients with a similar histopathology, cancer staging, and treatments regimen, have demonstrated variable clinical outcomes. Therefore the diagnostic tools for cancers have evolved from histology to methods such as genomic testing and chromosome karyotype analyses. Gene expression profiles can be used as unique molecular signatures to facilitate diagnosis, classify histopathologically similar tumors into biologically distinct subtypes [13] and identify patients with a high risk for occurrence and poor survival. Current cancer research is directed at deciphering the molecular mechanisms that dictate the pathogenesis and progression of the disease by translating basic science discoveries into the clinical practice of personalized medicine [14]. By bridging genomics and cellular behavior, proteomics and functional proteomic, are important tools in cancer research; comparative proteomics approaches are used to study the (i) tumor cell biology; (ii) identify the proteins, proteins complexes and specific cellular process related to cancer states and (iii) screen each biochemical, antigenic, and epigenetic cancer biomarkers for early disease diagnosis, tumor staging, tumor subtyping and determining the prognosis and response of patient to therapeutic interventions (Table 1). A brief overview of the contribution of proteomics to cancer research is provided below.

\section{Ovarian cancer}

Ovarian cancer is the most lethal gynecological malignancy due to the lack of highly sensitive and specific screening tools for detection of early-stage disease. Recent developments in the identification of potential biomarkers using proteomic technologies have resulted in improved positive predictive value. The glycoprotein antigen 125 (CA125 ) is the most commonly measured tumor marker for epithelial ovarian tumors which account for $85-90 \%$ of ovarian cancers, and it is used in the clinic to provide a prognosis, monitor progression, and optimize the care of women diagnosed with ovarian cancer [15]. However, the protein levels of CA-125 in the blood have been found to be elevated in only approximately $50 \%$ of the patients [16].

The pleomorphic cytokines interleukin 6 and 8 (IL-6 and IL8) are implicated in features of tumor growth, disease progression and / or treatment [17]. Compared with healthy individuals, elevated levels of mesothelin (MSLN) [18] and vascular endothelial growth factor (VEGF) [19] are detected in the sera of patients with ovarian carcinoma. VEGF inhibition decreases tumor growth and suppresses tumor invasion and metastasis [20]. Conversely, serum levels of full-length transthyretin (TTR), apolipoprotein A1 (Apo-A1) and transferrin (TF), an iron-binding transport protein, are reduced in the serum of patients with ovarian cancer [21]. Recently, a large number of combinations of biomarkers have been investigated to improve the sensitivity and specificity for the early detection of ovarian cancer.

\section{A: Biomarkers in cancer medicine.}

Type of Biomarker

Prognostic Biomarker

Diagnostic

Biomarker

Predictive Biomarker

Biomarker for Post-treatment Surveillance Monitoring Treatment Response B: Biomarkers in drug development.

Use of Biomarker
Risk Assessment,
Prevention
Diagnosis
Classification
Screening
Prognosis
Prediction of Treatment
Risk Stratification
Personalized Medicine
Monitoring Treatment Response

Target Verification
Early Compound Selection
Pharmacodynamics
Assays
Patient Selection for Clinical Trials
Surrogate Endpoint in Drug
Approval

\section{Clinical Goal}

To determine the cellular and molecular mechanisms of carcinogenesis in pre-neoplastic tissue

To determine the presence of cancer

To distinguish the specific type of cancer

To recognize early-stage cancer and administer early treatment.

Helps in estimating the likely outcome of the disease

Anticipate the response to specific treatment

Used in evaluating the probability of occurrence or recurrence of cancer

To select the therapy with the highest probability of being effective in a particular patient.

Used in assessing the effectiveness and adverse effects of a treatment.

\section{Discovery new drug target molecules}

Determine the most favorable compounds in terms of safety and efficacy

Ascertain the drug's effect and establish a dosing regimen. 
When combined with ApoA1 and TF, CA-125 yields a sensitivity and specificity of $96 \%$ and $98 \%$, respectively, for the detection of early-stage ovarian cancer [21]. Gorelik et al. identified a panel of biomarkers that combined CA-125 with epidermal growth factor (EGF), VEGF, IL-6 and IL-8 and achieved a sensitivity of $84 \%$ and a specificity of $95 \%$ for a total of 126 serum specimens [22]. CA-125, human epididymis protein 4 (HE4), carcinoembryonic antigen (CEA) and vascular cell adhesion molecule 1 (VCAM-1) have also been identified as a biomarker panel and tested using the sera from 139 patients with early-stage ovarian cancer, 149 patients with late-stage ovarian cancer and 1102 healthy women. This four-biomarker panel provided the highest diagnostic power of $86 \%$ sensitivity for early-stage and $93 \%$ sensitivity for latestage ovarian cancer, both with a specificity of $98 \%$ [23]. A different panel of biomarkers, consisting of IL- 8 and anti-IL-8, has been proposed by Lokshin [24]. This panel was tested using 211 serum specimens and was able to predict early ovarian cancer with $98 \%$ specificity and $65.5 \%$ sensitivity. HE4 also correlates with adenocarcinoma of the endometrium [25]; carbonic anhydrase 12 (CA-12), MSLN and HE4 have been proposed as a panel of ovarian cancer biomarkers [26]. These results, suggest that combinations of biomarkers may provide improved detection of disease as the first step of disease in a multimodal screening protocol.

\section{Prostate cancer}

Prostate cancer is one of the most commonly diagnosed malignancies and generally does not present any symptoms until it becomes locally advanced or metastatic disease; it is characterized by an unusual biological heterogeneity and demands distinctive classification [27]. Nonetheless, a greater number of patients are now diagnosed at an earlier stage due to recent improvements in advanced tools for the diagnosis of prostate cancer. Some of the most commonly used techniques to assess early stage prostate cancer are the DRE, TRUS [28] and prostate-specific antigen (PSA) blood test [29]. Current advancements in proteomics and other technologies have significantly accelerated the discovery and development of biomarkers for the diagnosis and prognosis of prostate cancer and include DNA-based markers, RNA-based biomarkers, and, particulary, protein biomarkers. Human prostatic acid phosphatase (PAP) and serum acid phosphatase (AP) were reportedly the first serum protein biomarkers for prostate cancer [30]. PSA is considered the most important test for detecting, staging, and monitoring early-stage prostate cancer [31,32]. PSA is a kallikrein protease with chymotryptic-like activity that was initially thought to be synthesized by the epithelial cells of the prostate and thus was used as a biomarker for the diagnosis and management of prostate cancer [33]. PSA was quantified in serum, and the highest levels were detected in men with prostate cancer. The main disadvantage of the PSA test is its lack of specificity; common pathological conditions such as benign prostatic hyperplasia and prostatitis can provide falsepositive results [34]. Overall, $70-75 \%$ of men who undergo biopsies due to abnormal PSA levels do not have cancer. To improve specificity, several variations of the basic PSA test have been proposed, such as the free PSA ratio, which compares the amount of free PSA circulating in the blood (unbound) to the amount attached to other blood proteins [30]. Methylacyl coenzyme A racemase (AMACR) is an enzyme localized in peroxisomes that is involved in fat metabolism and has been shown to function as a growth promoter in prostate cancer, independent of androgens $[35,36]$. Using various experimental methods and different prostate cancer specimens, the AMACR gene has been shown to be overexpressed in prostate cancer tissue at the mRNA and protein levels, making it a highly specific tissue biomarker that is currently used to facilitate in the pathological diagnosis $[37,38]$. Glutathione S-trasferase
(GST) is an example of a biomarker that has been extensively studied in prostate cancer, primarily as a tissue marker. GSTs are a ubiquitous family of multifunctional enzymes that conjugate reactive substrates to reduced glutathione (GSH) and are involved in detoxification $[39,40]$. Because cancer cells have high levels of free radicals, GST and GSH are up regulated under pathogenic conditions and play key roles in protecting cells against oxidative stress [41]. Chromogranin A (CRN-A), a member of the granin family of proteins, is an acidic protein that has been identified in all neuroendocrine cell types studied and is produced in larger amounts than other proteins secreted by the cells. The growth of prostate cells is regulated by peptides derived from CRN-A. Because it is produced and secreted by prostate cells, CRN-A has been assessed for its diagnostic and prognostic values, as a biomarker for prostate cancer [42].

\section{Hepatocellular carcinoma}

Hepatocellular carcinoma (HCC) is one of the most frequently diagnosed cancers worldwide. The majority of HCC develops in patients with a history of chronic hepatitis or cirrhosis, and the coexistence of inflammation and cirrhosis makes it much more difficult to provide an early diagnosis and prognostic assessment of HCC. Different genes have been studied with promising results, including telomerase reverse transcriptase (TERT), glypican 3 (GPC3), survivin (BIRC5), lymphatic vessel endothelial hyaluronan receptor 1 (LYVE1), $70 \mathrm{KDa}$ heat shock protein (HSP70) and insulin-like growth factors 1 (IGF-1)-associated genes. In recent years the gene-expression patterns associated with hepato-carcinogenesis have enabled clinicians to reach a conclusive differential diagnosis between HCC and the various pre-neoplastic stages. Other tumor markers, including protein induced by vitamin $\mathrm{K}$ absence (PIVKA), fraction L3 of alpha-fetoprotein (L3-AFP) and human hepatocyte growth factor (HGF), have been suggested to be the diagnostic markers of HCC [43]. Jia et al. [44] reported a significant increase in the level of five proteins, GPC3, paternally expressed 10, (PEG10), midkine (MDK), neuroserpin (SERPINI1) and the small molecular mass ubiquinone-binding protein (QP-C) in patients with HCC compared with healthy subjects. The combined score for these proteins can be used to accurately classify noncancerous hepatic tissues (100\%) and HCC (71\%). Consequently, these proteins may serve as biomarkers to aid in the diagnosis of HCC. A highly significant difference was observed in the serum level of calreticulin (CARL) and protein disulfide-isomerase A3 (PDIA3) fragments between patients with HCC and healthy individuals, as well as between patients with HCC and at-risk patients [45]. Altered glycosylation of several glycoproteins has been identified in patients with HCC. Among these, Golgi protein 73 (GP73) is overexpressed in patients with HCC, compared with healthy controls. Level of GP73 decreased following surgical resection of HCC lesions and increased with tumor recurrence [46]. The sensitivity and specificity of the serum level of GP73 for the diagnosis of HCC are $74.6 \%$ and $97.4 \%$, respectively. In addition, increased levels of GP73 have been detected in the sera of patients with HCC $[47,48]$. Charkady et al. [49] quantitated more than 600 proteins, among which 59 were upregulated and 92 proteins were downregulated in HCC compared with adjacent normal tissue. Some of the upregulated proteins included fibroleukin or fibrinogen-like protein 2 (FGL2), interferon induced $56-\mathrm{kDa}$ protein (IFN), milk fat globule-factor 8 (MFGE8) and myeloid-associated differentiation marker (MYADM). Another study showed the differential expression of s six proteins in the SMCC-7721 human HCC cell line: mitofilin (Mt-IM), endoplasmic reticulum protein 29 (ERp29), ubiquinolcytochrome C reductase complex core protein, (UQCRC1), peroxisomal enoyl CoA hydratase (ECH2), peroxiredoxin-4 (PRDX4), and probable 3- oxoacid CoA 
transferase 1 precursor (OXCT1) [50]. These proteins might promote tumorigenesis by (i) inhibiting cell death induced by several cancerrelated stresses and/or (ii) inhibiting apoptosis at multiple points in the apoptotic signaling pathway. Recently, Shen et al. [51] reported that the serum level of dickkopf-related protein 1 (DKK1) is a promising candidate for the diagnosis of HCC. DKK1 belongs to a family of secreted proteins that play an important role in HCC progression by promoting the cytoplasmic / nuclear accumulation of beta-catenin in HCC cells via the Wnt / beta-catenin signaling pathway [52]. Members of the heat shock proteins (HSPs) families, HSP70, HSP27 and HSP90, the nuclear heterogeneous ribonucleoproteins C1/C2 (HNRNPC) and the metastases suppressor nm23-H2 (NM323-H2) were up regulated in HCC samples [53]. Overexpression of these proteins was confirmed by western blot analysis and immunohistochemistry, suggesting their potential use as tumor markers. The HSPs are ubiquitous molecules that are induced in cells in response to various stress conditions. HSP70 and HSP27 are of special relevance in human cancer because they inhibit apoptosis. HSP70 and HSP27expression level might play an important role in hepatocarcinogenesis, and are closely related to tumor progression by promoting tumor cell proliferation. The use of a three marker panel consisting of HSP70, GPC3 and glutamine synthetase (GS), was found to increase the sensitivity and specificity (72 and $100 \%$, respectively) [54]. Using 2-DE image analysis and mass spectrometry identification eight proteins including HSP27, l'alfa-feto proteina (AFP), alfa 1 antitrypsin (A1AT) clusterin (CLU), caeruloplasmin (CP), haptoglobin a2 chain (HP2), TF and TTR showed significantly difference in the expression among healthy, and HCC groups. The hepatoma model displayed dynamic expression of hepatic TERT during HCC development and peaked at the stage of HCC formation. Abnormal expression of telomerase in liver tissues or in the peripheral blood could be a useful marker for the diagnosis of HCC $[53,55]$. The recent discovery of new therapeutic targets based on the molecular pathways that are involved in carcinogenesis has led to exciting discovering for targeted treatment strategies in tumor patients. Investigators have attempted to select individualized therapeutic options for patients based on the molecular profile of their tumor. This treatment modality will pave the way for personalized treatment of HCC.

\section{Proteomics in Heart Diseases}

Heart failure arising from systemic or specific heart-muscle diseases is one of the leading causes of morbidity and mortality [56]. The pathogenesis of the cardiac dysfunction remains largely unknown. In the last decade the quantification and characterization of changes in the proteome of cardiac myocytes at the onset of disease, have provided insight regarding the holistic response of injured tissue. A number of biomarkers have been established in clinical practice and reflects the decompensated hemodynamic status, myocardial strain, acute global stress response and other organ-specific injuries [57]. The natriuretic peptides, which include B-type natriuretic peptide (BNP) and the N-terminal fragment of its prohormone (NT-proBNP), as well as atrial natriuretic peptide (ANP), adrenomedullin (ADM) and the mid-regional fragment of the prohormone (MR-proANP), are currently the most widely used markers of myocardial strain and the gold standard for diagnosing heart failure and monitoring therapy. These prohormones are released in response to hemodynamic stress and processed into biologically active natriuretic peptides that can counteract the stress by inducing vasodilation, natriuresis and diuresis [58]. Recently, proteomics has been used to study variations in the proteome of patients with dilated cardiomyopathy (DCM). This pathological state is characterized by impaired of systolic function and is one of the most frequent causes of heart failure [59]. Patients with DCM showed significantly different expression pattern of a large number of proteins. Many of these proteins are classified into three broad functional classes: cytoskeletal and myofibrillar proteins, proteins associated with stress responses and proteins associated with mitochondria and energy production [60]. The levels of pyruvate dehydrogenase E1 (PDHA1) and pyruvate oxidoreductase (PORC) have been shown to be significantly increased in patients with DCM. Significant overexpression of dihydrolipoyl dehydrogenase (DLDH) and ATP synthase has also been observed. Considered together these results lead to the concept that mitochondrial dysfunction plays a critical role in the development of DCM [61]. In addition, a good correlation has been observed between the level of ATP and the mRNA and protein expression of the elongation factor Tu (EFTU) and the translation elongation factot $\mathrm{Tu}$ (TUFM), respectively. All these changes correlate well with the enhanced mitochondrial biogenesis that occurs in DMC [62]. The increased levels of the antioxidant protein thioredoxin-dependent peroxide reductase (PRDX3) are also of great importance; the overexpression of PRDX3 in mitochondria protects the heart against post-myocardial infarct remodeling and failure in mice by reducing left ventricular cavity dilation, fibrosis, and apoptosis [61]. Expression of the isoelectric isoform of the HSP27 increases during hypertrophy suggesting an altered stress response [63]. The mRNA and protein levels of the ubiquitin C-terminal hydrolase (UCH) enzyme increase five- and eight-fold respectively, in patients with DCM [64]. Overall, protein ubiquitination increases five-fold in patients with DCM compared with control subjects. These findings strengthens the hypothesis that inappropriate ubiquitin conjugation leads to proteolysis and the depletion of certain proteins in the DCM heart, which may contribute to the loss of normal cellular function in the diseased heart. In addition, cardiac antigens that produce specific antibody responses have been identified in vivo. Several of these antigens may be involved in the processes of acute and chronic rejection after cardiac transplantation [65], and they are currently being investigated as potential noninvasive markers. More recently, the phosphoproteome and protein kinase signal transduction pathways have been extensively studied and characterized in the myocardium [66]. The signal perturbations were mapped in postnatal mouse hearts, and revealed that protein mitogenactivated protein kinase kinase (MKK) promoted the development of cardiomyopathy by interacting wit multiple substrates. Clarification of the mechanisms leading to energetic derangement and, experimental silencing or overexpression of a specific gene in a murine model of DCM nay result in the identification of a promising therapeutic option to restore ventricular function in patients with DMC. Thus proteomics would allow us to improve and to develop etiology-specific therapies. Recently proteomics studies have led to the characterization of different expression patterns in primary cardiac tumors (PCTs). Amog these atrial myxoma, is the most common tumor and exhibits a heterogeneous phenotype, consisting of adult cells expressing specific protein antigens that are specific to various cell lineages, often within the same tumor, including antigen specific to epithelial, endothelial, myogenic, myofibroblast, neural and neuroendocrine cell lineages [67]. The detection of candidate protein biomarkers for cardiac myxoma is a complex because of the known heterogeneity and their relatively rare incidence; moreover, the use of proteomic profiling to discover biomarkers of for myxoma is still in its infancy.

\section{Proteomics in Neurodegenerative Disease}

Neurodegenerative diseases are a particularly devastating class of disorders that are characterized by neuronal impairment that leads to neuronal cell death. Diagnosis necessitates a brain biopsy or necropsy 
sample, although many sporadic cases have a typical clinical picture. Treatments aimed at inhibiting the neurodegenerative processes only focus on symptom management [68] and are likely to be most effective if the treatment is initiated as early as possible. In recent years, there has been a growing interest in applying proteomics to study on clinical diagnostics and predictive medicine for neurodegenerative disorders and to discover proteins that are associated wit pathogenic mechanisms for use as disease biomarkers; more advanced proteomic studies of degenerative diseases have been published [69-71]. Differences in the levels of various proteins in patients with neurodegenerative diseases compared with healthy control subject have been reported. It is interesting that the expression levels of the nerve growth factor (VGF), a neurosecretory protein that is known to regulate metabolism [72] and synaptic plasticity, are reduced in AD [73,74]; in FTD [75] and ALS [76]. Reduced expression of this protein seems to be a general phenomenon in diseases characterized by premature neuronal cells death, and thus may be a general marker for neurodegeneration. Increased levels of the microtubule-associated tau protein (MAPT) have been reported in the CSF of patients with AD, [77], vascular dementia (VD) [78] and Parkinson's disease (PD) [79] and they reflect the degree of neuronal degeneration and damage [80]. This phenomenon is supported by the demonstration of a marked transient increase in CSF-tau following acute stroke, with a positive correlation between the CSF-tau levels and the infarct size $[80,81]$. A marked increase in the levels of the 42 amino acid fragment of amyloid- $\beta$ protein $(A \beta 42)$ has been found in the CSF of $\mathrm{AD}$ patients [82]. The accumulation of $\mathrm{A} \beta 42$ fragment in the brain leads to neuronal damage, which in turn triggers inflammatory responses as the brain attempts to repair itself. This process is also thought to cause the formation of neurofibrillary tangles, consisting of tau protein witch contribute to neuronal damage and cause the symptoms of dementia [83]. Total and hyper-phosphorylated tau and A $\beta 42$ proteins have been established as candidate biomarkers for the early detection of disease before the onset of dementia [84-86]. Apolipoproteins (ApoA-I, ApoD and ApoE) are, also, involved in the pathology of neurodegenerative diseases. Recently, significantly lower levels of ApoA-I were observed in $\mathrm{AD}$ compared with controls serum [87]; this result is in agreement with the findings obtained for the CSF $[88,89]$. Increased ApoD levels have been described in $\mathrm{AD}[90,91]$ and more recently, in PD [92]. This protein is regarded as a potential marker of neuronal cell death [90-92]. Many studies note the importance of protein-protein interactions and PTMs in neurological diseases, including ubiquitination, glycosylation, glycation, and, particulary, phosphorylation. A proteomic analysis of the CSF revealed different abundances of two proteins, designated p130 and p131, witch are members of the 14-3-3 family, and can discriminate between Creutzfeldt-Jakob disease (CJD) and other types of dementia with a sensitivity of $88 \%$ and specificity of $99 \%$ [93]. These proteins are also highly abundant in some patients with other neurological disorders without dementia, and they can reflect neuronal damage rather than disease pathogenesis. Alterations in the expression or PTMs of a number of proteins, including parkin (PARK2) [94], tau [90] and superoxide dismutase (SOD1) $[95,96]$, have been linked to neurodegenerative diseases, such as PD, AS, and ALS. Recent proteomic investigations of the pathogenic mechanisms underlying neurodegenerative disorders have focused mainly on $\mathrm{AD}$ and $\mathrm{PD}$ witch are the most common neurodegenerative diseases.

\section{Proteomics in Parkinson's disease (PD)}

In 1984, Harrington and colleagues showed for the first time, evidence that the protein expression pattern in the CSF of PD patients differs from healthy controls [97]. The first unbiased profile of the human SNpc identified 44 proteins nine of witch were significantly differentially expressed in PD compared with controls tissues [98]. The $\mathrm{L}$ and $\mathrm{M}$ neurofilament chains were downregulated in $\mathrm{PD}$ specimens. In addition, the levels of mitochondrial complex III, ATP synthase D chain, (ATPD), complexin I (CPLX1), calcium channel delta-subunit (CCHLA2) and fatty-acid binding protein (FABPs) were significantly increased in PD samples compared with control samples [99]. Using proteomics, Werner and colleagues identified 222 differentially expressed proteins in the brains of patients with PD. This work confirmed the above results and identified other differentially expressed proteins including V-type ATPase A1 (V-ATPase A1), ferritin H (FTH), ferritin L (FTL) and mortalin (HSPA9) [100]. Current research investigating the etiology of $\mathrm{PD}$ has recognized that mitochondrial impairments, oxidative stress and altered calcium homeostasis are the major idiopathic factors in PD [101-104]. A panel of eight CSF proteins, brain-derived neurotrophic factor (BDNF), IL-8, vitamin $\mathrm{D}$ binding protein (VDBP), $\beta 2$-microglobulin (B2M), APOAII and APOE, tau and $A \beta 1-42$, have been tested as markers in different and larger sets of patients/subjects, and can classify PD patients with sensitivity and specificity values of 95\% each [101]. Furthermore, the other differentially expressed proteins includes Glutathione S-Transferase (GST), Glutathione S-transferase P (GSTP1), glutathione S-transferase omega 1 (GSTO1) muscarinic 3 (M3), and SH3-binding glutamic acid-rich like protein (SH3BGRL), all of which were expressed at higher levels in patients with PD than in healthy controls. Overall PD patients showed increased levels of the oxidized DNA, proteins and lipids and decreased levels of reduced GSH. Based on the proteomic data, Jami et al. [105] hypothesized that L-3, 4-dihydroxyphenylalanine (L-DOPA), witch is normally used for PD medications, reverses some of the negative effects of $\mathrm{H}_{2} \mathrm{O}_{2}$.

In addition to the sporadic forms, of $\mathrm{PD}$, there are dominant and recessive forms of familial PD that are linked to mutations in specific genes. As for autosomal dominant forms, mutations in three genes have been identified: $\alpha$-synuclein (PARK1 and PARK4) UCL1 (ubiquitin carboxy-terminal hydrolase L1, PARK5) and LRRK2 (leucine-rich repeat kinase 2 PARK8). The autosomal recessive forms of Parkinsonism are linked to mutations in the parkin (PARK2, the most common) PINK1 (PARK6), and DJ-1 (PARK7) genes, and are characterized by early onset of the disease [106]. All of these mutations affect molecular processes that are involved in the pathogenesis of $\mathrm{PD}$, such as mitochondrial activity (DJ-1 and PINK1), oxidative stress (a-synuclein, DJ-1), intracellular signaling (DJ-1, LRRK2) and, in particularly, protein aggregation, cytoskeleton structure-dynamics, and calcium homeostasis (parkin, a-synuclein, UCHL1) [107-111]. Some of the above proteins are emerging candidate biomarkers; $a$-synuclein and DJ-1 have been identified in the CSF and plasma of PD patients [112-116]. Reduced levels of $\alpha$ - synuclein in the CSF have been reported to be associated with increased severity of Parkinsonism in patients with PD [112-114]. DJ-1 level was found to increase in the CSF and plasma of PD patients, and correlated with the disease severity $[112,114]$. The glial related proteins (glial fibrillary acidic protein (GFAP), glial maturation factor beta (GMFB), galectin 1 (LGALS1) and sorcin (SRI) are differentially upregulated in PD and it has been shown to serve as biomarker of neurotoxicity [117]. The upregulationn of proteins belonging to other metabolic pathways that are not usually associated with PD have also observed, including S-adenosyl homocysteine hydrolase 1 (SAHcy), aldehyde dehydrogenase A1 (ADH1A1) and cellular retinol-binding protein 1 (CRBP1), annexin $\mathrm{V}$, beta-tubulin cofactor A (TBCA) and coactosin-like protein 1(COLT1) [100]. A recent study showed that $\mathrm{CP}$ and Apo-H appeared to differentiate PD patients from healthy controls as well as from patients 
with other diseases. As an important iron transport protein CP is of great interest because it has been suggested to play a central role in $\mathrm{PD}$ the pathogenesis of PD $[118,119]$. Chromogranin B (CHGB) together with Apo-H provide increased sensitivity to differentiate PD patients from healthy controls. Although CHGB alone cannot differentiate AD or PD from controls, the ratio between CHGA and CHGB may be a correcting factor for the neuropeptides that are present in human CSF [120].

\section{Proteomics in Alzheimer's disease (AD)}

Several proteins that are involved in inflammation and the complement system are significantly up regulated in patients with $\mathrm{AD}$; chemokines and chemokine receptors are also up regulated in $\mathrm{AD}$ brain cells and contributed to plaque-associated inflammation and neurodegeneration processes [121]. The increased levels of CSF chemokine ligand 2 (CCL2), witch plays a significant role in the inflammatory processes in $\mathrm{AD}$, correlate positively with the level of p-tau [122]. Consequently, CCL2 may serve as a potential biomarker to monitor the progression of the pathologic state of $\mathrm{AD}$. The expression of the $40-\mathrm{kDa}$ secreted glycoprotein YKL-40, also known as chitinase 3-like 1 (CHI3L1), which participates in a inflammation and tissue remodeling, is elevated in early $\mathrm{AD}$ but its physiological functions remain unclear. The ratio of YKL- 40 to $A \beta 42$ predicts cognitive impairment as well as the best CSF biomarkers (A $\beta 42$, $t$-tau, and p-tau) [123], suggesting that it may be a potential biomarker for preclinical AD. Visinin-like protein-1 (VILIP-1) is a potential marker of neuronal injury. Investigation of CSF VILIP-1 as a diagnostic and prognostic marker in early AD indicates that VILIP-1 levels in the CSF can differentiate individuals with $\mathrm{AD}$ from cognitively normal controls and from patients with other dementias, and that CSF VILIP-1 / A $\beta 42$ as well as tau / $A \beta 42$ and p-tau181 / $A \beta 42$ predicts cognitive impairment $[122,123]$. S100A7, a small calcium-binding protein that is involved in immune responses was recently found to be elevated in the CSF and brain of patients with $\mathrm{AD}$ and the levels of this protein correlated with disease severity [124] S100A7 has the potential to serve as another biomarker of $\mathrm{AD}$.

\section{Metaproteomics}

The human gastro-intestinal (GI) tract contains a vast and diverse microbial ecosystem: the microbiome that has co-evolved with our species in terms of our metabolic and nutritional requirements $[125,126]$ and is essential for human health $[127,128]$. The GI microbiota perform a large number of important functions that define the physiology of the host, such as immune system maturation [129] conditioning and response [130]; the intestinal response to epithelial cell injury [131]; and xenobiotic [132] and energy metabolism [133]. The microbiota of the GI tract also influences drug metabolism and toxicity [134], dietary calorific bioavailability [135], and post-surgical recovery [136]. Perturbations of the composition of the microbiota, also known as dysbiosis, have been recognized in various diseases. The microbiota have been directly implicated in the etiopathogenesis of a number of pathological states such as cardiovascular disease, [137], inflammatory bowel diseases (IBDs) [138], autism [9] and obesity [10], (Figure 3). The phylogenetic characterization of the microbiota of individuals with disease, compared with apparently healthy individuals, is the main approach to examining changes in the composition of the intestinal microbiota [139]. Systems biology approaches based on next generation 'omics' technologies (summarized in Figure 2), have stimulated the field of metaproteomics [139-142] and can now describe the gut microbiome at detailed genetic and functional (genomic, transcriptomic, proteomic

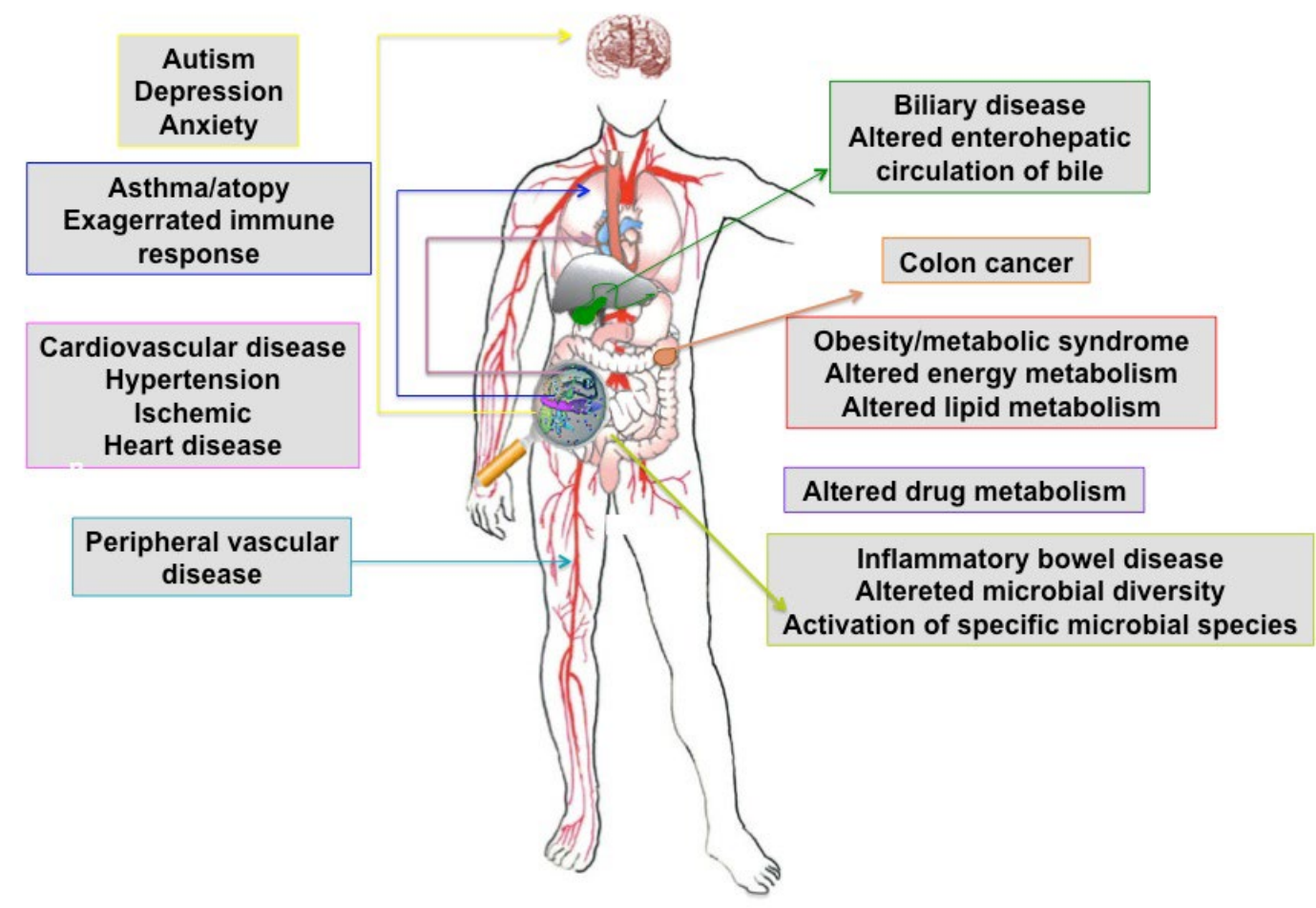

Figure 3: Systemic diseases directly influenced by gut microbiota.

Several human disease are associated with disorder of microbiome. Diseases that are directly influenced by the gut microbial content are highlighted [10]. 
and metabolic) levels, providing new insights into their importance in human health, and they can be used to map microbiome variability between species, individuals and populations [139]. This has led to the concept of 'global metabolic profiling', which provides a unique overview of the metabolic state of an individual because it is able to indirectly measure complex transgenomic co-metabolic interactions that are vital for human health, and which are often modulated by disease [143-146].

Along with the reconstruction of the metabolic pathways associated with the GI tract, metaproteomic approach (Table 2) provides information regarding the role of the gut microbiota in metabolic syndromes, inflammation and obesity [10]. The absence of intestinal microorganisms has been shown to protect germ-free mice against the development of obesity after being fed a high-fat, sugar-rich diet [145]. Furtemore, colonization of germ-free mice with the microbiota of obese mice induced a significantly greater increase in body fat weight compared with germ-free mice colonized with the microbiota of lean mice [10]. These experiments demonstrated that the intestinal microbiota is involved in the regulation of fat storage. Introduction of the intestinal microbiota resulted in an increase in the metabolic rate, modulation of de novo lipogenesis and an increase in the uptake of monosaccharides from the intestine [146]. Based on these results, it has been hypothesized that obese individuals convert food into usable and stored fat energy more efficiently than learn individuals [147]. There is increasing evidence that dysbiosis of the intestinal microbiota plays a role in the pathogenesis of IBD $[11,148]$. Chronic IBDs affect the entire intestinal tract and are characterized by discontinuous inflammation of the epithelial lining and deep ulcers. Crohn's disease (CD) and ulcerative colitis (UC) are the most form of prevalent IBD witch can be associated with an increased risk of colorectal carcinoma [12]. Numerous studies have compared the composition of the intestinal microbiota of IBD patients with that of healthy individuals. The observed compositional and functional changes in patients with IBD suggest that the intestinal microbiota plays an important role in the etiology and pathogenesis of IBD.

However, metaproteomics studies are just emerging as there are various practical challenges including the high complexity of the microbial ecosystem, difficulties in separating human and prokaryotic proteins, and the fact that the databases have just been developed due to the advances in metagenomic sequencing. In the near future, metagenomic and metaproteomic studies will provide more insight regarding the role of the GI microbiota in diseases.

\section{Proteogenomics}

Proteogenomics integrates proteomic and genomic data and is an emerging and promising area of study in omics research [6]. The goal is to develop novel methods to integrate and visualize the proteomic and genomic data to better understand biological processes. Proteogenomics originates from advances in proteomics that have made it feasible to obtain coverage comparable to that achieved using genomics and transcriptomics and it is a direct method for effective

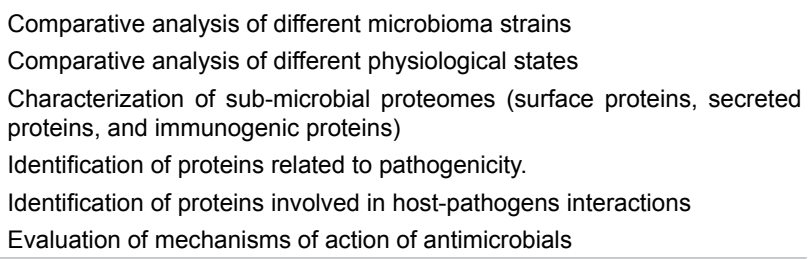

Table 2: Targeted proteomic approaches to microbial pathogens. systems biology studies. The base concept is that protein data can shed light on the consequences of various genomic features, such as the determination of whether a specific genetic variant may become a functional protein. By matching deep MS-based proteomics to a personalized database constructed from a sample-specific genome and transcriptome, thousands of peptides that would otherwise escape identification can be identified. One requirement for effective systems biology studies is sufficient proteomics coverage. In the last few years, it has become routine in some laboratories to obtain coverage in the range of 10,000 to 12,000 proteins $[149,150]$. Using integrated proteogenomics technologies, Munoz and colleagues identified 13,078 human and 10,637 mouse proteins, including 39,941 peptides that were not previously described in the human dataset of the Peptide Atlas and 224 novel human and 122 novel mouse peptides, which mapped to 164 and 101 genomic loci, respectively [151]. Using high resolution isoelectric focusing, they also probed a six-reading-frame translation of the human and mouse genomes and identified 98 and 52 previously undiscovered protein-coding loci, respectively [151]. Heck et al. [152], have completed a proteogenomics study of rat liver tissue, and identified 13,088 proteins by integrating whole genome sequencing, RNA-seq, and mass spectrometry-based proteomics resulting in one of the most comprehensive proteome analyses performed to date. By integrating the genomics data, they validate 1,195 gene predictions, 83 splice events, 120 proteins with nonsynonymous variants, and 20 protein isoforms with nonsynonymous RNA editing, providing a greater understanding of the RNA editing process. The effort also provided biological insights including information concerning outstanding questions regarding RNA editing-a process in which an RNA sequence is modified after it has been generated. To highlight the relationship between genomic (DNA and RNA) and proteomic (protein) abnormalities, a number of researchers, independently or as part of large-scale initiatives, have systematically identified proteins from geomically characterized tumors, such as those from TCGA program, to decipher the complex proteogenomic relationship between genomic and proteomic abnormalities and to provide a deeper understanding of cancer biology. The CPTAC program is currently analyzing more than 300 samples from colorectal, breast, and ovarian cancer. The first set of proteogenomic data was made public in September 2013 (http://proteomics.cancer.gov/). Integrative proteogenomic analyses using genomic, transcriptomic, and proteomic technologies, appears to be the future techniques of choice for understanding the genetic control of molecular dynamics and phenotypic diversity in a systemwide manner [153]. The integration and interrogation of the proteomic and genomic data will provide potential biomarker candidates, which will be prioritized for downstream-targeted proteomic analyses. These biomarker targets will be used to create quantitative multiplex assays to verify and prescreen the relevance of the targets in clinically relevant and unbiased samples. The outcomes from this approach will provide the community with verified biomarkers that can be used for clinical qualification studies; high quality and publicly accessible datasets, and analytically validated, multiplex, quantitative protein / peptide assays and their associated high quality reagents for the research and clinical communities.

\section{Concluding Remarks}

Integrative analyses of different data types can to correctly delineate the effects of genomic and transcriptomic variations on molecular processes and cellular functioning that delineate the proteomic phenotype in specific pathophysiological states. Due the potential to decode the pathogenic mechanisms underlying diseases, human proteomics greatly impact on medicine with the prospects that 
results of proteomic disease investigations will overcome some of the limitations the current diagnostic and therapeutic methods.

Future proteomics research, by supporting technology optimization, development, and data standardization, can successfully advancing the translation of proteomic findings into clinically relevant applications along with a rigorous assessment of the biospecimens and the generation of quality data through the implementation of quality assessment criteria at each step of biomarker development and will expedite the development of individualized medicine.

\section{References}

1. Venter JC, Adams MD, Myers EW, Li PW, Mural RJ, et al. (2001) The sequence of the human genome. Science 291: 1304-1351.

2. Hawkins RD, Hon GC, Ren B (2010) Next-generation genomics: an integrative approach. Nat Rev Genet 11: 476-486.

3. Pradet-Balade B, Boulmé F, Beug H, Müllner EW, Garcia-Sanz JA (2001) Translation control: bridging the gap between genomics and proteomics? Trends Biochem Sci 26: 225-229.

4. Soon WW, Hariharan M, Snyder MP (2013) High-throughput sequencing for biology and medicine. Mol Syst Biol 9: 640.

5. Scherp P, Ku G, Coleman L, Kheterpal I (2011) Gel-based and gel-free proteomic technologies. Methods Mol Biol 702: 163-190.

6. Altelaar AF, Munoz J, Heck AJ (2013) Next-generation proteomics: towards an integrative view of proteome dynamics. Nat Rev Genet 14: 35-48.

7. Mesri M (2014) Advances in Proteomic Technologies and Its Contribution to the Field of Cancer. Adv Med 2014: 238045

8. Hong ML, Jiang N, Gopinath S, Chew FT (2006) Proteomics technology and therapeutics. Clin Exp Pharmacol Physiol 33: 563-568.

9. Finegold SM (2008) Therapy and epidemiology of autism-clostridial spores as key elements. Med Hypotheses 70: 508-511.

10. Kinross JM, Darzi AW, Nicholson JK (2011) Gut microbiome-host interactions in health and disease. Genome Med 3: 14.

11. Sartor RB (2008) Microbial influences in inflammatory bowel diseases. Gastroenterology 134: 577-594.

12. Kavanagh DO, Carter MC, Keegan D, Doherty G, Smith MJ, et al. (2014) Management of colorectal cancer in patients with inflammatory bowel disease. Tech Coloproctol 18: 23-28

13. Ramaswamy S, Tamayo P, Rifkin R, Mukherjee S, Yeang CH, et al. (2001) Multiclass cancer diagnosis using tumor gene expression signatures. Proc Nat Acad Sci U S A 98: 15149-15154.

14. Koomen JM, Haura EB, Bepler G, Sutphen R, Remily-Wood ER, et al. (2008) Proteomic contributions to personalized cancer care. Mol Cell Proteomics 7: 1780-1794.

15. Bast RC Jr, Badgwell D, Lu Z, Marquez R, Rosen D, et al. (2005) New tumor markers: CA125 and beyond. Int J Gynecol Cancer 15 Suppl 3: 274-281.

16. Nossov V, Amneus M, Su F, Lang J, Janco JM, et al. (2008) The early detection of ovarian cancer: from traditional methods to proteomics. Can we really do better than serum CA-125? Am J Obstet Gynecol 199: 215-223.

17. Macciò A, Madeddu C (2013) The role of interleukin- 6 in the evolution of ovarian cancer: clinical and prognostic implications-a review. J Mol Med (Berl) 91: $1355-1368$

18. McIntosh MW, Drescher C, Karlan B, Scholler N, Urban N, et al. (2004) Combining CA 125 and SMR serum markers for diagnosis and early detection of ovarian carcinoma. Gynecol Oncol 95: 9-15.

19. Duncan TJ, Al-Attar A, Rolland P, Scott IV, Deen S, et al. (2008) Vascular endothelial growth factor expression in ovarian cancer: a model for targeted use of novel therapies? Clin Cancer Res 14: 3030-3035.

20. Byrne AT, Ross L, Holash J, Nakanishi M, Hu L, et al. (2003) Vascular endothelial growth factor-trap decreases tumor burden, inhibits ascites, and causes dramatic vascular remodeling in an ovarian cancer model. Clin Cancer Res 15: 5721-5728.
21. Ahmed N, Oliva KT, Barker G, Hoffmann P, Reeve S, et al. (2005) Proteomic tracking of serum protein isoforms as screening biomarkers of ovarian cancer. Proteomics 5: 4625-4636.

22. Gorelik E, Landsittel DP, Marrangoni AM, Modugno F, Velikokhatnaya L, et al. (2005) Multiplexed immunobead-based cytokine profiling for early detection of ovarian cancer. Cancer Epidemiol Biomarkers Prev 14: 981-987.

23. Yurkovetsky Z, Skates S, Lomakin A, Nolen B, Pulsipher T, et al. (2010) Development of a multimarker assay for early detection of ovarian cancer. $\mathrm{J}$ Clin Oncol 28: 2159-2166.

24. Lokshin AE, Winans M, Landsittel D, Marrangoni AM, Velikokhatnaya L, et al. (2006) Circulating IL-8 and anti-IL-8 autoantibody in patients with ovarian cancer. Gynecol Oncol 102: 244-251.

25. Huhtinen K, Suvitie P, Hiissa J, Junnila J, Huvila J, et al. (2009) Serum HE4 concentration differentiates malignant ovarian tumours from ovarian endometriotic cysts. Br J Cancer 21: 1315-1319.

26. Anderson GL, McIntosh M, Wu L, Barnett M, Goodman G, et al. (2010) Assessing lead time of selected ovarian cancer biomarkers: a nested casecontrol study. J Natl Cancer Inst 102: 26-38.

27. Smith RA, Mettlin CJ, Eyre H (2003) Cancer Medicine: Cancer Screening and Early Detection. In: Kufe DW, Pollock RE, Weichselbaum RR, Bast Jr. RC Gansler TS, et al. (Eds) Cancer Medicine. Hamilton, Canada: BC Decker Inc.

28. Assinder SJ, Nicholson H (2007) Prostate Disease: Prostate hyperplasia and prostate cancer and prostatitis. In: Kandeel EF (Ed) Pathophysiology and Treatment of Male Sexual and Reproductive Dysfunction. Marcel Dekker Inc: New York, NY, USA.

29. Seikkula H, Pettersson K, Boström PJ (2015) PSA and blood test diagnostics of prostate cancer. Duodecim 131: 1547-1552.

30. Madu CO, Lu Y (2010) Novel diagnostic biomarkers for prostate cancer. J Cancer 1: 150-177.

31. Lilja H, Ulmert D, Vickers AJ (2008) Prostate-specific antigen and prostate cancer: prediction, detection and monitoring. Nat Rev Cancer 8: 268-278.

32. Rao AR, Motiwala HG, Karim OM (2008) The discovery of prostate-specific antigen. BJU Int 101: 5-10.

33. Thorek DL, Evans MJ, Carlsson SV, Ulmert D, Lilja H (2013) Prostate-specific kallikrein-related peptidases and their relation to prostate cancer biology and detection. Established relevance and emerging roles. Thromb Haemost 3: 484 492.

34. Oh WK, Hurwitz M, D'Amico AV, et al. (2003) Neoplasms of the Prostate. In Kufe DW, Pollock RE, Weichselbaum RR, Bast Jr. RC, Gansler TS, et al. (Eds) Cancer Medicine. Hamilton, Canada: BC Decker Inc.

35. Kuefer R, Varambally S, Zhou M, Lucas PC, Loeffler M, et al. (2002) alphaMethylacyl-CoA racemase: expression levels of this novel cancer biomarker depend on tumor differentiation. Am J Pathol 161: 841-848.

36. Zha S, Ferdinandusse S, Denis S, Wanders RJ, Ewing CM, et al. (2003) Alphamethylacyl-CoA racemase as an androgen-independent growth modifier in prostate cancer. Cancer Res 63: 7365-7376.

37. Jiang Z, Wu CL, Woda BA, Iczkowski KA, Chu PG, et al. (2004) Alphamethylacyl-CoA racemase: a multi-institutional study of a new prostate cancer marker. Histopathology 45: 218-225.

38. Rubin MA, Zhou M, Dhanasekaran SM, Varambally S, Barrette TR, et al. (2002) alpha-Methylacyl coenzyme $A$ racemase as a tissue biomarker for prostate cancer. JAMA 287: 1662-1670.

39. Hayes JD, Pulford DJ (1995) The glutathione S-transferase supergene family: regulation of GST and the contribution of the isoenzymes to cancer chemoprotection and drug resistance. Crit Rev Biochem Mol Biol 30: 445-600.

40. Lee WH, Morton RA, Epstein JI, Brooks JD, Campbell PA, et al. (1994) Cytidine methylation of regulatory sequences near the pi-class glutathione $S$-transferase gene accompanies human prostatic carcinogenesis. Proc Natl Acad Sci U S A 91: 11733-11737.

41. Hayes JD, Pulford DJ (1995) The glutathione S-transferase supergene family: regulation of GST and the contribution of the isoenzymes to cance chemoprotection and drug resistance. Crit Rev Biochem Mol Biol 30: 445-600.

42. Deftos LJ (1998) Granin-A, parathyroid hormone-related protein, and calcitonin gene products in neuroendocrine prostate cancer. Prostate Suppl 8: 23-31. 
43. Forner A, Rodríguez de Lope C, Reig M, Rimola J, Varela M (2008) Early diagnosis of primary liver cancer: imaging versus genetics. Rev Esp Enferm Dig 100: 423-429.

44. Jia HL, Ye QH, Qin LX, Budhu A, Forgues M, et al. (2007) Gene expression profiling reveals potential biomarkers of human hepatocellular carcinoma. Clin Cancer Res 13: 1133-1139.

45. Chignard N, Shang S, Wang H, Marrero J, Bréchot C, et al. (2006) Cleavage of endoplasmic reticulum proteins in hepatocellular carcinoma: Detection of generated fragments in patient sera. Gastroenterology 130: 2010-2022.

46. Kladney RD, Cui X, Bulla GA, Brunt EM, Fimmel CJ (2002) Expression of GP7, a resident Golgi membrane protein, in viral and nonviral liver disease. Hepatology 35: 1431-1440.

47. Riener MO, Stenner F, Liewen H, Soll C, Breitenstein S, et al. (2009) Golgi phosphoprotein 2 (GOLPH2) expression in liver tumors and its value as a serum marker in hepatocellular carcinomas. Hepatology 49: 1602-1609.

48. Mao Y, Yang H, Xu H, Lu X, Sang X, et al. (2010) Golgi protein 73 (GOLPH2) is a valuable serum marker for hepatocellular carcinoma. Gut 59: 1687-1693.

49. Chaerkady R, Harsha HC, Nalli A, Gucek M, Vivekanandan P, et al. (2008) A quantitative proteomic approach for identification of potential biomarkers in hepatocellular carcinoma. J Proteome Res 7: 4289-4298.

50. Feng Y, Tian ZM, Wan MX, Zheng ZB (2007) Protein profile of human hepatocarcinoma cell line SMMC-7721: identification and functional analysis. World J Gastroenterol 13: 2608-2614.

51. Shen Q, Fan J, Yang XR, Tan Y, Zhao W, et al. (2012) Serum DKK1 as a protein biomarker for the diagnosis of hepatocellular carcinoma: a large-scale, multicentre study. Lancet Oncol 13: 817-826.

52. Yu B, Yang X, Xu Y, Yao G, Shu H, et al. (2009) Elevated expression of DKK1 is associated with cytoplasmic/nuclear beta-catenin accumulation and poor prognosis in hepatocellular carcinomas. J Hepatol 50: 948-957.

53. Yao DF, Dong ZZ, Yao M (2007) Specific molecular markers in hepatocellular carcinoma. Hepatobiliary Pancreat Dis Int 6: 241-247.

54. Di Tommaso L, Franchi G, Park YN, Fiamengo B, Destro A, et al. (2007) Diagnostic value of HSP70, glypican, and glutamine synthetase in hepatocellular nodules in cirrhosis. Hepatology 45: 725-734.

55. Sun W, Xing B, Sun Y, Du X, Lu M, et al. (2007) Proteome analysis of hepatocellular carcinoma by two-dimensional difference gel electrophoresis: novel protein markers in hepatocellular carcinoma tissues. Mol Cell Proteomics 6: 1798-1808.

56. Heart Disease and Stroke Statistics (2004) Update, AH. Association.

57. Maisel AS, Choudhary R (2012) Biomarkers in acute heart failure-state of the art. Nat Rev Cardiol 9: 478-490.

58. Iqbal N, Wentworth B, Choudhary R, Landa Ade L, Kipper B, et al. (2012) Cardiac biomarkers: new tools for heart failure management. Cardiovasc Diagn Ther 2: 147-164.

59. Jefferies JL, Towbin JA (2010) Dilated cardiomyopathy. Lancet 375: 752-762.

60. McGregor E, Dunn MJ (2006) Proteomics of the heart: unraveling disease. Circ Res 98: 309-321.

61. Roselló-Lletí E, Tarazón E, Barderas MG, Ortega A, Otero M, et al. (2014) Heart mitochondrial proteome study elucidates changes in cardiac energy metabolism and antioxidant PRDX3 in human dilated cardiomyopathy. PLoS One 9: e112971.

62. Ahuja P, Wanagat J, Wang Z, Wang Y, Liem DA, et al. (2013) Divergent mitochondrial biogenesis responses in human cardiomyopathy. Circulation 127: 1957-1967.

63. McGregor E, Dunn MJ (2006) Proteomics of the heart: unraveling disease. Circ Res 98: 309-321.

64. Mearini G, Schlossarek S, Willis MS, Carrier L (2008) The ubiquitin-proteasome system in cardiac dysfunction. Biochim Biophys Acta 1782: 749-763.

65. Wheeler $\mathrm{CH}$, Collins A, Dunn MJ, Crisp SJ, Yacoub MH, et al. (1995) Characterization of endothelial antigens associated with transplant-associated coronary artery disease. J Heart Lung Transplant 14: S188-S197.

66. Fernando P, Deng W, Pekalska B, DeRepentigny Y, Kothary R, et al.
(2005) Active kinase proteome screening reveals novel signal complexity in cardiomyopathy. Mol Cell Proteomics 4: 673-682.

67. Messina F, Romano P, Crosca S (2016) Atrial myxomas and different clinical presentations. Int J Cardiol 203: 1136-1137.

68. Reitz C, Rogaeva E, Foroud T, Farrer LA (2011) Genetics and genomics of late-onset Alzheimer's disease and its endophenotypes. Int J Alzheimers Dis 2011: 284728

69. Abdi F, Quinn JF, Jankovic J, McIntosh M, Leverenz JB, et al. (2006) Detection of biomarkers with a multiplex quantitative proteomic platform in cerebrospinal fluid of patients with neurodegenerative disorders. J Alzheimers Dis 9: 293-348.

70. Rüetschi U, Zetterberg H, Podust VN, Gottfries J, Li S, et al. (2005) Identification of CSF biomarkers for frontotemporal dementia using SELDI-TOF. Exp Neuro 196: 273-281.

71. Ranganathan S, Williams E, Ganchev P, Gopalakrishnan V, Lacomis D, et al. (2005) Proteomic profiling of cerebrospinal fluid identifies biomarkers for amyotrophic lateral sclerosis. J Neurochem 95: 1461-1471.

72. Hahm S, Mizuno TM, Wu TJ, Wisor JP, Priest CA, et al. (1999) Targeted deletion of the Vgf gene indicates that the encoded secretory peptide precursor plays a novel role in the regulation of energy balance. Neuron 23: 537-548.

73. Carrette O, Demalte I, Scherl A, Yalkinoglu O, Corthals G, et al. (2003) A panel of cerebrospinal fluid potential biomarkers for the diagnosis of Alzheimer's disease. Proteomics 3: 1486-1494.

74. Simonsen AH, McGuire J, Podust VN, Hagnelius NO, Nilsson TK, et al. (2007) A novel panel of cerebrospinal fluid biomarkers for the differential diagnosis of Alzheimer's disease versus normal aging and frontotemporal dementia. Dement Geriatr Cogn Disord 24: 434-440.

75. Asano T, Koizumi S, Takagi A, Hatori T, Kuwabara K, et al. (2011) Identification of a novel biomarker candidate, a $4.8-\mathrm{kDa}$ peptide fragment from a neurosecretory protein VGF precursor, by proteomic analysis of cerebrospinal fluid from children with acute encephalopathy using SELDI-TOF-MS. BMC Neurol 11: 101.

76. Pasinetti GM, Ungar LH, Lange DJ, Yemul S, Deng H, et al. (2006) Identification of potential CSF biomarkers in ALS. Neurology 66: 1218-1222.

77. Green AJ, Harvey RJ, Thompson EJ, Rossor MN (1999) Increased tau in the cerebrospinal fluid of patients with frontotemporal dementia and Alzheimer's disease. Neurosci Lett 259: 133-135.

78. Blennow K, Wallin A, Agren H, Spenger C, Siegfried J, et al. (1995) Tau protein in cerebrospinal fluid: a biochemical marker for axonal degeneration in Alzheimer disease? Mol Chem Neuropathol 26: 231-245.

79. Molina L, Touchon J, Herpé M, Lefranc D, Duplan L, et al. (1999) Tau and apo $\mathrm{E}$ in CSF: potential aid for discriminating Alzheimer's disease from other dementias. Neuroreport 10: 3491-3495.

80. Hesse C, Rosengren L, Vanmechelen E, Vanderstichele $H$, Jensen C, et al (2000) Cerebrospinal fluid markers for Alzheimer's disease evaluated after acute ischemic stroke. J Alzheimers Dis 2: 199-206.

81. Hesse C, Larsson H, Fredman P, Minthon L, Andreasen N, et al. (2000) Measurement of apolipoprotein $\mathrm{E}$ (apoE) in cerebrospinal fluid. Neurochem Res 25: 511-517.

82. Butterfield DA, Swomley AM, Sultana R (2013) Amyloid $\beta$-peptide (1-42)-induced oxidative stress in Alzheimer disease: importance in disease pathogenesis and progression. Antioxid Redox Signal 19: 823-835.

83. Huang SM, Mouri A, Kokubo H, Nakajima R, Suemoto T, et al. (2006) Neprilysinsensitive synapse-associated amyloid-beta peptide oligomers impair neuronal plasticity and cognitive function. J Biol Chem 28: 17941-17951.

84. Hansson O, Zetterberg H, Buchhave P, Londos E, Blennow K, et al. (2006) Association between CSF biomarkers and incipient Alzheimer's disease in patients with mild cognitive impairment: a follow-up study. Lancet Neurol 5: 228-234.

85. Herukka SK, Hallikainen M, Soininen H, Pirttilä T (2005) CSF Abeta42 and tau or phosphorylated tau and prediction of progressive mild cognitive impairment. Neurology 64: 1294-1297.

86. Parnetti L, Lanari A, Silvestrelli G, Saggese E, Reboldi P (2006) Diagnosing prodromal Alzheimer's disease: role of CSF biochemical markers. Mech Ageing Dev 127: 129-132. 
87. Liu HC, Hu CJ, Chang JG, Sung SM, Lee LS, et al. (2006) Proteomic identification of lower apolipoprotein A-I in Alzheimer's disease. Dement Geriatr Cogn Disord 21: 155-161.

88. Castaño EM, Roher AE, Esh CL, Kokjohn TA, Beach T (2006) Comparative proteomics of cerebrospinal fluid in neuropathologically-confirmed Alzheimer's disease and non-demented elderly subjects. Neurol Res 28: 155-163.

89. Puchades M, Hansson SF, Nilsson CL, Andreasen N, Blennow K, et al. (2003) Proteomic studies of potential cerebrospinal fluid protein markers for Alzheimer's disease. Brain Res Mol Brain Res 118: 140-146.

90. Terrisse L, Poirier J, Bertrand P, Merched A, Visvikis S, et al. (1998) Increased levels of apolipoprotein D in cerebrospinal fluid and hippocampus of Alzheimer's patients. J Neurochem 71: 1643-1650.

91. Thomas EA, Laws SM, Sutcliffe JG, Harper C, Dean B, et al. (2003) Apolipoprotein D levels are elevated in prefrontal cortex of subjects with Alzheimer's disease: no relation to apolipoprotein E expression or genotype. Biol Psychiatry 54: 136-141.

92. Ordoñez C, Navarro A, Perez C, Astudillo A, Martínez E, et al. (2006) Apolipoprotein $D$ expression in substantia nigra of Parkinson disease. Histol Histopathol 21: 361-366.

93. Zerr I, Bodemer M, Gefeller O, Otto M, Poser S, et al. (1998) Detection of 14-33 protein in the cerebrospinal fluid supports the diagnosis of Creutzfeldt-Jakob disease. Ann Neurol 43: 32-40.

94. LaVoie MJ, Ostaszewski BL, Weihofen A, Schlossmacher MG, Selkoe DJ (2005) Dopamine covalently modifies and functionally inactivates parkin. Nat Med 11: 1214-1221.

95. Kabashi E, Valdmanis PN, Dion P, Rouleau GA (2007) Oxidized / misfolded superoxide dismutase-1: the cause of all amyotrophic lateral sclerosis? Ann Neurol 62: 553-559.

96. Rakhit R, Crow JP, Lepock JR, Kondejewski LH, Cashman NR, et al. (2004) Monomeric $\mathrm{Cu}, \mathrm{Zn}$-superoxide dismutase is a common misfolding intermediate in the oxidation models of sporadic and familial amyotrophic lateral sclerosis. $J$ Biol Chem 279: 15499-15504.

97. Harrington MG, Merril CR (1984) Two-dimensional electrophoresis and "ultrasensitive" silver staining of cerebrospinal fluid proteins in neurological diseases. Clin Chem 30: 1933-1937.

98. Basso M, Giraudo S, Corpillo D, Bergamasco B, Lopiano L, et al. (2004) Proteome analysis of human substantia nigra in Parkinson's disease. Proteomics 4: 3943-3952.

99. Przedborski S, Vila M, Jackson-Lewis VV, Dawson TM (2000) Reply: a new look at the pathogenesis of Parkinson's disease Trends Pharmacol Sci 21: 165.

100. Werner CJ, Heyny-von Haussen R, Mall G, Wolf S (2008) Proteome analysis of human substantia nigra in Parkinson's disease. Proteome Sci 6: 8.

101.Zhang J, Sokal I, Peskind ER, Quinn JF, Jankovic J, et al. (2008) CSF multianalyte profile distinguishes Alzheimer and Parkinson diseases. Am J Clin Pathol 129: 526-529.

102. Branco DM, Arduino DM, Esteves AR, Silva DF, Cardoso SM, et al. (2010) Cross-talk between mitochondria and proteasome in Parkinson's disease pathogenesis. Front Aging Neurosci 2: 17.

103. Banerjee R, Starkov AA, Beal MF, Thomas B (2009) Mitochondrial dysfunction in the limelight of Parkinson's disease pathogenesis. Biochim Biophys Acta 1792: 651-663.

104.Surmeier DJ, Guzman JN, Sanchez-Padilla J, Schumacker PT (2011) The role of calcium and mitochondrial oxidant stress in the loss of substantia nigra pars compacta dopaminergic neurons in Parkinson's disease. Neuroscience 198: 221-231.

105.Jami MS, Pal R, Hoedt E, Neubert TA, Larsen JP, et al. (2014) Proteome analysis reveals roles of L-DOPA in response to oxidative stress in neurons. BMC Neurosci 2202: 15-93.

106. Fasano M, Bergamasco B, Lopiano L (2007) The proteomic approach in Parkinson's disease. Proteomics Clin Appl 1: 1428-1435.

107. Golbe LI (1999) Alpha-synuclein and Parkinson's disease. Mov Disord 14: 6-9.

108. Lotharius J, Brundin P (2002) Pathogenesis of Parkinson's disease: dopamine, vesicles and alpha-synuclein. Nat Rev Neurosci 3: 932-942.
109.Bonifati V, Oostra BA, Heutink P (2004) Unraveling the pathogenesis of Parkinson's disease-the contribution of monogenic forms. Cell Mol Life Sci 61: $1729-1750$.

110. Gasser T (2005) Genetics of Parkinson's disease. Curr Opin Neurol 18: 363 369.

111. Lippolis R, Siciliano RA, Pacelli C, Ferretta A, Mazzeo MF, et al. (2015) Altered protein expression pattern in skin fibroblasts from parkin-mutant earlyonset Parkinson's disease patients. Biochim Biophys Acta 1852: 1960-1970.

112. El-Agnaf OM, Salem SA, Paleologou KE, Curran MD, Gibson MJ, et al. (2006) Detection of oligomeric forms of alpha-synuclein protein in human plasma as a potential biomarker for Parkinson's disease. FASEB J 20: 419-425.

113. Maita C, Tsuji S, Yabe I, Hamada S, Ogata A, et al. (2008) Secretion of DJ-1 into the serum of patients with Parkinson's disease. Neurosci Lett 431: 86-89.

114. Tokuda T, Salem SA, Allsop D, Mizuno T, Nakagawa M, et al. (2006) Decreased alpha-synuclein in cerebrospinal fluid of aged individuals and subjects with Parkinson's disease. Biochem Biophys Res Commun 349: 162 166.

115. Waragai M, Wei J, Fujita M, Nakai M, Ho GJ, et al. (2006) Increased leve of DJ-1 in the cerebrospinal fluids of sporadic Parkinson's disease. Biochem Biophys Res Commun 345: 967-972.

116. Waragai M, Nakai M, Wei J, Fujita M, Mizuno H, et al. (2007) Plasma levels of DJ-1 as a possible marker for progression of sporadic Parkinson's disease. Neurosci Lett 425: 18-22.

117. Saracchi E, Fermi S, Brighina L (2013) Emerging candidate biomarkers for Parkinson's disease: a review. Aging Dis 5: 27-34.

118. Hochstrasser H, Bauer P, Walter U, Behnke S, Spiegel J, et al. (2004) Ceruloplasmin gene variations and substantia nigra hyperechogenicity in Parkinson disease. Neurology 63: 1912-1917.

119. Tórsdóttir G, Kristinsson J, Sveinbjörnsdóttir S, Snaedal J, Jóhannesson T (1999) Copper, ceruloplasmin, superoxide dismutase and iron parameters in Parkinson's disease. Pharmacol Toxicol 85: 239-243.

120. Eder U, Fischer-Colbrie R, Kogner P, Leitner B, Bjellerup P, et al. (1998) Levels and molecular forms of chromogranins in human childhood neuroblastomas and ganglioneuromas. Neurosci Lett 253: 17-20.

121. Corrêa JD, Starling D, Teixeira AL, Caramelli P, Silva TA (2011) Chemokines in CSF of Alzheimer's disease patients. Arq Neuropsiquiatr 69: 455-459.

122. Craig-Schapiro R, Perrin RJ, Roe CM, Xiong C, Carter D, et al. (2010) YKL40: a novel prognostic fluid biomarker for preclinical Alzheimer's disease. Biol Psychiatry 68: 903-912.

123. Tarawneh R, D’Angelo G, Macy E, Xiong C, Carter D, et al. (2011) Visininlike protein-1: diagnostic and prognostic biomarker in Alzheimer disease. Ann Neurol 70: 274-285.

124. Qin W, Ho L, Wang J, Peskind E, Pasinetti GM (2009) S100A7, a novel Alzheimer's disease biomarker with non-amyloidogenic alpha-secretase activity acts via selective promotion of ADAM-10. PLoS One 4: e4183.

125. Dethlefsen L, Huse S, Sogin ML, Relman DA (2008) The pervasive effects of an antibiotic on the human gut microbiota, as revealed by deep 16S rRNA sequencing. PLoS Biol 6: e280.

126. Jernberg C, Löfmark S, Edlund C, Jansson JK (2010) Long-term impacts of antibiotic exposure on the human intestinal microbiota. Microbiology 156 : 3216-3223.

127. Bengmark S (1998) Ecological control of the gastrointestinal tract. The role of probiotic flora. Gut 42: 2-7.

128. Gill SR, Pop M, Deboy RT, Eckburg PB, Turnbaugh PJ, et al. (2006) Metagenomic analysis of the human distal gut microbiome. Science 312 : 1355-1359.

129. Mazmanian SK, Liu CH, Tzianabos AO, Kasper DL (2005) An immunomodulatory molecule of symbiotic bacteria directs maturation of the host immune system. Cell 122: 107-118.

130. Macpherson AJ, Gatto D, Sainsbury E, Harriman GR, Hengartner H, et al (2000) A primitive T cell-independent mechanism of intestinal mucosal IgA responses to commensal bacteria. Science 288: 2222-2226.

131.Rakoff-Nahoum S, Paglino J, Eslami-Varzaneh F, Edberg S, Medzhitov R 
(2004) Recognition of commensal microflora by toll-like receptors is required for intestinal homeostasis. Cell 118: 229-241.

132. Wilson ID, Nicholson JK (2009) The role of gut microbiota in drug response. Curr Pharm Des 15: 1519-1523.

133. Turnbaugh PJ, Ley RE, Mahowald MA, Magrini V, Mardis ER, et al. (2006) An obesity-associated gut microbiome with increased capacity for energy harvest. Nature 444: 1027-1031.

134. Clayton TA, Lindon JC, Cloarec O, Antti H, Charuel C, et al. (2006) Pharmacometabonomic phenotyping and personalized drug treatment. Nature 440: 1073-1077.

135. Hooper LV, Gordon JI (2001) Commensal host-bacterial relationships in the gut. Science 292: 1115-1118.

136. Kinross JM, Alkhamesi N, Barton RH, Silk DB, Yap IK, et al. (2011) Global metabolic phenotyping in an experimental laparotomy model of surgical trauma. J Proteome Res 10: 277-287.

137. Holmes E, Loo RL, Stamler J, Bictash M, Yap IK, et al. (2008) Human metabolic phenotype diversity and its association with diet and blood pressure. Nature 453: 396-400.

138. Marchesi JR, Holmes E, Khan F, Kochhar S, Scanlan P, et al. (2007) Rapid and noninvasive metabonomic characterization of inflammatory bowel disease. J Proteome Res 6: 546-551.

139. VerBerkmoes NC, Denef VJ, Hettich RL, Banfield JF (2009) Systems biology: Functional analysis of natural microbial consortia using community proteomics. Nat Rev Microbiol 7: 196-205.

140. Seifert J, Taubert M, Jehmlich N, Schmidt F, Völker U, et al. (2012) Proteinbased stable isotope probing (protein-SIP) in functional metaproteomics. Mass Spectrom Rev 31: 683-697.

141. Hettich RL, Pan C, Chourey K, Giannone RJ (2013) Metaproteomics: harnessing the power of high performance mass spectrometry to identify the suite of proteins that control metabolic activities in microbial communities. Anal Chem 9: 4203-4214.

142. Kolmeder CA, de Vos WM2 (2014) Metaproteomics of our microbiome developing insight in function and activity in man and model systems. J Proteomics 97: 3-16.
143. Kanazawa H, Nagino M, Kamiya S, Komatsu S, Mayumi T, et al. (2005) Synbiotics reduce postoperative infectious complications: a randomized controlled trial in biliary cancer patients undergoing hepatectomy. Langenbecks Arch Surg 390: 104-113.

144. Alverdy JC, Chang EB (2008) The re-emerging role of the intestinal microflora in critical illness and inflammation: why the gut hypothesis of sepsis syndrome will not go away. J Leukoc Biol 83: 461-466.

145. Bäckhed F, Manchester JK, Semenkovich CF, Gordon JI (2007) Mechanisms underlying the resistance to diet-induced obesity in germ-free mice. Proc Natl Acad Sci U S A 104: 979-984.

146. Bäckhed F, Ding H, Wang T, Hooper LV, Koh GY, et al. (2004) The gut microbiota as an environmental factor that regulates fat storage. Proc Natl Acad Sci U S A 101: 15718-15723.

147. Ferrer M, Ruiz A, Lanza F, Haange SB, Oberbach A, et al. (2013) Microbiota from the distal guts of lean and obese adolescents exhibit partial functional redundancy besides clear differences in community structure. Environ Microbiol 15: 211-226.

148. Sokol H, Seksik P (2010) The intestinal microbiota in inflammatory bowel diseases: time to connect with the host. Curr Opin Gastroenterol 26: 327-331.

149. Munoz J, Low TY, Kok YJ, Chin A, Frese CK, et al. (2011) The quantitative proteomes of human-induced pluripotent stem cells and embryonic stem cells. Mol Syst Biol 7: 550.

150. Nagaraj N, Wisniewski JR, Geiger T, Cox J, Kircher M, et al. (2011) Deep proteome and transcriptome mapping of a human cancer cell line. Mol Syst Biol 7: 548.

151. Branca RM, Orre LM, Johansson HJ, Granholm V, Huss M, et al. (2014) HiRIEF LC-MS enables deep proteome coverage and unbiased proteogenomics. Nat Methods 11: 59-62.

152. Low TY, van Heesch S, van den Toorn H, Giansanti P, Cristobal A, et al. (2013) Quantitative and qualitative proteome characteristics extracted from indepth integrated genomics and proteomics analysis. Cell Rep 5: 1469-1478.

153. Renuse S, Chaerkady R, Pandey A (2011) Proteogenomics. Proteomics 11: 620-630. 